\title{
A Ten-Year Review of Primary Postpartum Haemrrhage at a University Teaching Hospital, Sagamu, Nigeria: A Case-Control Study
}

\author{
Mustafa Adelaja Lamina*, Monday Ikhile \\ Maternal and Fetal Unit, Department of Obstetrics and Gynaecology, Olabisi Onabanjo University Teaching \\ Hospital, Sagamu, Nigeria \\ Email: ${ }^{*}$ ademustapha2003@yahoo.co.uk
}

Received 18 January 2015; accepted 27 February 2015; published 28 February 2015

Academic Editor: Shunji Suzuki, Japanese Red Cross Katsushika Maternity Hospital, Japan

Copyright (C) 2015 by authors and Scientific Research Publishing Inc.

This work is licensed under the Creative Commons Attribution International License (CC BY). http://creativecommons.org/licenses/by/4.0/

(c) (i) Open Access

\section{Abstract}

Objective: To determine the incidence of primary postpartum haemorrhage, identify risk/aetiological factors contributing to primary postpartum haemorrhage and review the different therapeutic approaches in the management of primary postpartum haemorrhage. Method: A retrospective case-control study of all patients with primary postpartum haemorrhage from January 1, 2001 to December 31, 2010 at Olabisi Onabanjo University Teaching Hospital, Sagamu, Nigeria. Result: In the period under review, 272 cases of primary postpartum haemorrhage were documented while there were a total of 5929 deliveries, giving an incidence of 1 in 26 (25.6\%). The average blood loss in the cases reviewed was $1550 \mathrm{mls}$ whilst in the controls, the average blood loss was $200 \mathrm{mls}$. There was statistical significant difference between the grandmultiparous cases and grandmultiparous controls $(58.4 \%$ versus $16.5 \%, 0 R=6.74, p<0.05)$, suggesting that grandmultiparity may be an implicated factor in primary postpartum haemorrhage. In the unbooked cases, retained placenta was the major cause of primary postpartum haemorrhage constituting 109 (51.7\%), whereas in booked cases, uterine atony contributed $70.5 \%$ to primary postpartum haemorrhage. Four maternal deaths were recorded giving a case fatality rate of $1.5 \%$; all were unbooked. Conclusion: Postpartum haemorrhage ranks high in the list of causes of maternal death and the case fatality rate can be very high. Prevention is the key to reducing the incidence of PPH and its sequale, with preventive measures based upon the identification of risk factors, surveillance of women at risk and seemingly not at risk and avoidance of procedure during delivery which could potentially result in complications.

\footnotetext{
${ }^{*}$ Corresponding author.
} 


\section{Keywords}

\section{Primary Postpartum Haemorrhage, Atony, Retained Placenta, Genital Tract Laceration, Uterine Inversion}

\section{Introduction}

The World Health Organization (WHO) currently defines primary postpartum haemorrhage (PPH) as blood loss in the first 24 hours after the birth of the baby equal to or in excess of $500 \mathrm{mls}$ [1].

Another proposed definition for PPH is a $10 \%$ change in haematocrit from antepartum levels [2]. This is a retrospective diagnosis with shortcomings in clinical settings.

Combs [3] has suggested a clinical definition of "need for blood transfusion", but this is complicated by variations in practice pattern and attitudes towards transfusion by both patients and physicians. Therefore, the diagnosis of PPH remains a subjective clinical assessment that includes any amount of blood loss that threatens the woman's haemodynaemic [4]. The clinical estimation of blood loss is notoriously inaccurate [5].

Postpartum haemorrhage ranks high in the list of causes of maternal death and the case fatality rate can be very high [6]. In Britain, the risk of maternal death from PPH is 1 in 100,000 deliveries while in developing countries the risk is in the order of 1 in 1000 deliveries [7]. Similarly in Nigeria, postpartum haemorrhage was found to have a case fatality rate of $2.2 \%$ at a Teaching Hospital [8]. While a haemorrhage of $500-800$ mls may not be serious for a well nourished and healthy woman, it could lead to disastrous consequences among women with chronic anaemia due to nutritional deficiency and malaria, and also in parturients with dehydration or severe pre-eclampsia and eclampsia [9].

Excessive bleeding affects 5\% - 15\% of women postpartum [3]. The leading causes in the developing world are failure of the uterus to contract well enough to arrest bleeding at the placental site (atony), retained placenta, retained products of conception or blood clots. Others include genital tract injury and coagulation disorders. The acronym four T's have been used to denote the causes of PPH and include Tone, Tissue, Trauma and Thrombin [10].

Risk factors associated with the incidence of postpartum haemorrhage include primiparity, previous third stage complications, anaemia, pregnancy induced hypertension, grandmultiparity and multiple pregnancy among others [11].

The consequences therefore, of excessive haemorrhage in a parturient woman in the developing world who often comes in labour with a low haemoglobin status are quite enormous [4]. It could range from a prolonged debilitating recovery period, through poor wound healing and uncontrollable sepsis to maternal death [6].

Primary postpartum haemorrhage in our environment is still a leading cause of maternal mortality and morbidity, and commonest single preventable cause of maternal mortality still remains haemorrhage amongst which atonic postpartum haemorrhage accounts for $90 \%$ of primary postpartum haemorrhage, the most important [4] [9].

The principle of management is to ascertain the cause of the bleeding and initiate prompt measures to control it. Interval between delivery, diagnosis of primary postpartum haemorrhage and the start of resuscitation with appropriate medical or surgical measures is an important prognostic factor for subsequent maternal morbidity and mortality associated with primary postpartum haemorrhage.

Though researches into obstetric risk factors have been difficult to undertake in the developing world where hospital-based obstetric patients are poorly representative of the general population of parturient women and data from non-hospital-based deliveries are difficult to obtain. However, policy decisions must be based on the known incidence of primary postpartum haemorrhage, current trend in the pattern and general clinical manifestation in this environment. The major associated aetiogical factors and the basis for patient susceptibility will serve as an overall guide in the training and development of personnel.

Therefore, the objective of this study is to determine the incidence of primary postpartum haemorrhage, identify risk/aetiological factors contributing to primary postpartum haemorrhage and review the different therapeutic approaches in the management of primary postpartum haemorrhage. 


\section{Methodology}

This is a retrospective case-control study of all patients with primary postpartum haemorrhage from January 1 , 2001 to December 31, 2010. The information for the study was obtained from case notes retrieved from the Medical Information Department and correlated with the admission registers in the obstetric ward. The record of total deliveries was collated for the period under review. The ethical approval to conduct this study was given by Health Research Ethics Committee of the hospital.

During this period, there were a total of 6929 deliveries and 281 cases of primary postpartum haemorrhage were documented. However, only 272 case files (96.8\%) could be retrieved for data analysis. Data on variables such as booking status, age, parity, previous history of postpartum haemorrhage, sources of referral for unbooked cases, the mode of delivery, identified causes of haemorrhage, estimated blood loss and measures instituted to arrest haemorrhage was collated and entered into a data sheet. A study of 544 randomly selected controls was done to emphasize the risk factors for postpartum haemorrhage. Two controls per case were randomly selected from the remaining births by selecting the case just before and the case just after the primary postpartum haemorrhage from the birth records.

Data analysis was carried out using SPSS for Windows version 17.0. Percentages, the chi-squared test and the student t-test were used for comparison where appropriate. Differences were considered as significant when Pvalue is less than 0.05 .

\section{Results}

In the period under review, 272 cases of primary postpartum haemorrhage were documented while there were a total of 5929 deliveries, giving an incidence of 1 in 26 (25.6\%). Data analysis revealed that the average blood loss in the cases reviewed was $1550 \mathrm{mls}$ in the immediate postpartum; whilst in the controls, the average blood loss was $200 \mathrm{mls}$. The estimated blood loss ranged between $500 \mathrm{mls}$ and $2900 \mathrm{mls}$ in cases while in the controls it was $100-450 \mathrm{mls}$.

Four maternal deaths were recorded giving a case fatality rate of $1.5 \%$. All the patients were unbooked, and the causes of death in three patients were severe (irreversible) hypovolaemic shock and the fourth death was due to complications that developed with unrecognised haemoglobinopathy.

A previous history of postpartum haemorrhage was obtained in 17 cases (6.3\%) while no such history was obtained in controls. The booking status of the cases revealed that 63 (23.2\%) were booked while 209 (76.8\%) were unbooked. The difference among booked and unbooked cases was statistically significant (OR $=0.09, \mathrm{P}<$ 0.05). In the controls, 139 (25.6\%) and 405 (74.4\%) were booked and unbooked respectively. The difference in the number of booked and unbooked for cases and controls was not statistically significant.

Table 1 showed the age distribution of the cases and controls. While $9.6 \%$ of cases were in the $15-19$ year age bracket, a larger proportion of cases were within the combined 20 - 34 year age group bracket, accounting for $66.3 \%$ of the cases while $9.6 \%$ of cases were aged between $35-39$ and $3.1 \%$ above 40 years. The difference within the age group distribution was statistically significant $(\mathrm{P}<0.05)$. Very young maternal age does not seem to be associated with primary postpartum haemorrhage.

Table 2 showed the parity distribution of cases and controls. Among the cases, there was statistical significant difference between grandmultiparous patients on one hand, and primiparae and multipara on the other hand

Table 1. Age distribution of patients with primary postpartum haemorrhage.

\begin{tabular}{ccccc}
\hline Age (years) & Cases & Percentage & Controls & Percentage \\
\hline $15-19$ & 26 & 9.6 & 109 & 20.0 \\
$20-24$ & 61 & 22.4 & 90 & 16.5 \\
$25-29$ & 87 & 32.0 & 181 & 33.3 \\
$30-34$ & 63 & 23.2 & 95 & 17.5 \\
$35-39$ & 27 & 9.9 & 52 & 9.6 \\
40 and above & 8 & 2.9 & 17 & 3.1 \\
Total & 272 & 100.0 & 544 & 100.0 \\
\hline
\end{tabular}


(grandmultiparae vs primiparae, $\mathrm{OR}=7.25, \mathrm{P}<0.05$ ); (grandmultiparae vs multiparae, $\mathrm{OR}=4.14, \mathrm{P}<0.05$ ). Also between cases and controls, there was statistical significant difference between the grandmultiparous cases and grandmultiparous controls $(\mathrm{OR}=6.74, \mathrm{P}<0.05)$, suggesting that grandmultiparity may be an implicated factor in primary postpartum haemorrhage.

Sources of referral for the unbooked cases showed that the Traditional Birth Attendants (TBA) referred 81 (37.4\%) of the cases, 62 (29.4\%) were referred from the Primary Health Centers while 35 (16.6\%) and 33 (15.6\%) were referred from General Hospitals and Private Clinics/Hospitals respectively.

Table 3 showed the mode of delivery amongst cases and controls. Of the 272 cases, 179 (65.8\%) had spontaneous vertex delivery, twin delivery occurred in 61 (22.4\%) and assisted breech delivery occurred in 17 (6.3\%). The larger contribution following twin deliveries in the cases is however, noted $(\mathrm{OR}=2.28, \mathrm{P}<0.05)$.

Table 4 illustrated the causes of primary postpartum haemorrhage. The unbooked cases constituted 211 (77.6\%) of cases studied. In the unbooked cases, retained placenta was the major cause of primary postpartum haemorrhage constituting 109 (51.7\%) followed by retained products of conception, which made up of 45 (21.3\%) of the unbooked cases. Whereas in booked cases, uterine atony contributed $70.5 \%$ to primary postpartum haemorrhage, followed by retained products of conception (16.4\%). There was no case of retained placenta in booked cases.

The blood loss among the cases ranged between 500 - $2900 \mathrm{mls}$ while among the controls, the blood loss ranged between 100 - $450 \mathrm{mls}$.

Table 2. Parity distribution among patients.

\begin{tabular}{ccccc}
\hline Parity & Cases & Percentage & Controls & Percentage \\
\hline 1 & 44 & 16.2 & 155 & 28.5 \\
$2-4$ & 69 & 25.4 & 299 & 55 \\
5 and above & 159 & 58.4 & 90 & 16.5 \\
Total & 272 & 100.0 & 544 & 100.0 \\
\hline
\end{tabular}

Table 3. Mode of delivery amongst patients with primary postpartum haemorrhage.

\begin{tabular}{ccccc}
\hline Type & Cases & Percentage & Controls & Percentage \\
\hline Spontaneous vertex delivery & 179 & 65.8 & 438 & 80.5 \\
Assisted breech delivery & 17 & 6.3 & 17 & 3.1 \\
Twins delivery & 61 & 22.4 & 61 & 11.2 \\
Forceps delivery & 4 & 1.5 & 19 & 1.7 \\
Vacuum extraction & 8 & 2.9 & - & 3.5 \\
Destructive operation & 3 & 1.1 & - \\
\hline
\end{tabular}

Table 4. Causes of primary postpartum haemorrhage.

\begin{tabular}{|c|c|c|c|c|}
\hline Cause & Unbooked cases & Percentage & Booked cases & Percentage \\
\hline Uterine atony & 13 & 6.1 & 43 & 70.5 \\
\hline Cervical tear & 17 & 8.1 & 8 & 13.1 \\
\hline Vaginal laceration & 9 & 4.3 & - & - \\
\hline Perineal tear & 8 & 3.8 & - & - \\
\hline Episiotomy & 10 & 4.7 & - & - \\
\hline Retained products of conception & 45 & 21.3 & 10 & 16.4 \\
\hline Retained placenta & 109 & 51.7 & - & - \\
\hline Total & 211 & 100.0 & 127 & 100.0 \\
\hline
\end{tabular}


The therapeutic measures instituted for primary postpartum haemorrhage included use of intravenous oxytocin in 114 (41.9\%) of cases while additional ergometrine maleate was given in 103 (37.9\%) of cases. Manual vacuum aspiration/curettage was used 157 (57.7\%) of cases with 52 (19.1\%) requiring manual removal of placenta. Genital tract laceration was repaired in 35 (12.9\%) of cases and 8 (2.9\%) of the cases required hysterectomy while more than half $(153,56.3 \%)$ of the patients had blood transfusion. Many of the patients required more than one therapeutic measure.

\section{Discussion}

The most common cause of obstetric haemorrhage is postpartum haemorrhage [12] and its incidence following delivery in the developed world is 5.8\% [4]. This study revealed an incidence of $25.6 \%$ or 1 in 26 deliveries, which corroborates the findings at the University College Hospital, Ibadan, [11] which put the incidence at $3.4 \%$.

Predisposing factors to postpartum haemorrhage are recognized important risk components in the development of this third stage complication of labour. Sometimes, however, the condition is unexpected. Most episodes of PPH are due to atony of the uterus after the delivery of the infant [7] [13]. In this study, the commonest cause of primary postpartum haemorrhage was uterine atony for the booked patients, which constituted $71.7 \%$ in this group. In a study on postpartum haemorrhage in Zimbabwe [6], uterine atony, vaginal lacerations and cervical tears are the major sources of primary postpartum haemorrhage.

For the unbooked patients in this study, the commonest cause of primary postpartum haemorrhage was retained placenta, which accounted for more than half $(51.7 \%)$ of unbooked cases. Other causes identified in other studies, which include retained placental fragments and lower genital tract lacerations were also identified in this study. Uterine inversion and blood coagulopathy said to be rare causes of profound blood loss, shock and death [13]-[15] were not encountered in this study. Poverty, ignorance, strong traditional beliefs and the fear of surgery force many women to choose delivery at home, religious houses or with TBA's with attendant risks of precipitate or prolonged labour, sepsis, uterine rupture and a complicated third stage of labour, all of which can lead to PPH.

Majority of the patients (77.6\%) was unbooked. Traditional Birth Attendants and Community Health Extension Workers conducted $66.8 \%$ of their deliveries, indicating that these groups probably attend to most deliveries in our environment. All the mortalities occurred in the unbooked cases.

Increasing maternal age and grandmultiparity have been widely acclaimed in previous studies as very crucial factors [16]. However, some recent studies have not given credence to this view; rather an elevated risk with low parity [17] [18]. These studies, which revealed a close association between low parity and primary postpartum haemorrhage was compatible with the findings of the WHO and other workers [1] [4] [16]. Adetoro in 1992, in a study conducted in Ilorin, Nigeria, observed that primary postpartum haemorrhage occurred more in both the primipara and grandmultiparae compared with controls [13]. In this review however, grandmultiparity but not primiparity appears to be a risk factor for primary postpartum haemorrhage while no increased risk of haemorrhage with increasing maternal age was observed.

Other well-known factors associated with postpartum haemorrhage like a previous history of postpartum haemorrhage, multiple pregnancies and operative vaginal deliveries were also found to occur slightly more in the cases when compared with controls in this study.

On the contrary, Selo-Ojeme and Okonofua [19] reported only prolonged second and third stages of labour and non-use of oxytocics after delivery as significant risk factors for PPH and not grandmultiparity, pimigravidity and previous episodes of PPH.

The therapeutic measures employed in the management of primary postpartum haemorrhage in this survey were not exhaustive. Additional medical therapies, which were not used include intramyometrial injection of prostaglandin F2 $\alpha$ (Carboprost ${ }^{\mathrm{R}}, 1 \mathrm{mg}$ ) which gives appreciable results within 2 - 3 minutes [20] [21]. Also, vasopressin injection, 20 units diluted in $100 \mathrm{ml}$ normal saline and injected ( $1 \mathrm{ml}$ at a time) at the bleeding site while avoiding intravascular injection is effective [22].

Published randomized controlled trials have shown Misoprostol as an important prophylaxis against PPH [23] [24]. The benefits of Misoprostol are its low cost and non-parental (oral, sublingual, rectal) administration. Also important, especially in the developing world, is that Misoprostol can be stored for long periods of time at room temperature, thus making it very useful for non-medical personnel and in peripheral units [23]. A synthetic ana- 
logue of oxytocin, carbetocin, has been found to reduce the need for additional pharmacological management of the third stage of labour. This long-acting drug has a rapid onset of action and a half-life of 40 minutes as compared to oxytocin, which is $4-10$ minutes [25].

There is no evidence that uterine packing is of any value and so was not employed in this center. If atony fails to respond to medical treatment, another cause for the bleeding must be excluded and an examination under anaesthesia should be performed [26]. Haemorrhage uncontrollable by basic measures or medical agents would require surgical intervention. But the decision to undertake surgery is sometimes emotionally delayed to the detriment of the patients. Such delay rather than the lack of surgical expertise accounts for most deaths [27].

The surgical options include ligation of pelvic arteries done vaginally or via laparotomy, application of uterine compression sutures, placement of figure of eight sutures on the bleeding placenta site and hysterectomy. The ligation of pelvic arteries reduces the pulse pressure in these vessels and allows coagulation to take place. The ligation of the uterine arteries could be done transabdominally by placing a single absorbable suture around the uterine vessels just above the bladder flap encompassing a portion of the myometrium. A second stitch is placed beneath the ovarian ligament adjacent to arrest further bleeding from the source [28] [29].

If bleeding persists after inserting these stitches, both internal iliac arteries should be ligated before hysterectomy is considered. The ligation of pelvic vessels could also be approached vaginally. The vaginal route is simple and facilitated by pregnancy related oedema and the procedure includes anterior colpotomy, reflection of the vesico-uterine fascia and ligation of the uterine arteries at their arch [29]. Surgical compression suture of uterine atony (B-Lynch suture) is appropriate where bimanual compression produces a decrease in vaginal bleeding before surgery [30]. It has gained popularity due to its simplicity and has brought reduction in hysterectomies, blood transfusions, maternal deaths and improvement in patients' satisfaction. Each suture included the full thickness of the uterine wall with the knot tied to the serosa not including the uterine vessels. The bleeding will completely cease after the insertion of four to five sutures [29]. The placement of several figure of eight sutures using absorbable polyglycolic sutures in the bleeding placental site is recommended when there is intractable placental site bleeding at caesarean section especially with lower uterine segment implantation of the placenta.

Hysterectomy should be performed as a last resort when other conservative methods of control of obstetric haemorrhage have failed [31]. Hysterectomy was the instituted form of management in $3.2 \%$ of the cases studied while other surgical measures were not instituted. The advantages of emergency hysterectomy in the situation of massive haemorrhage are the ability to remove the source of bleeding and the procedure of hysterectomy which, albeit more technically difficult in this situation is still a familiar operation to any obstetrician/gynaecologist [32]. The disadvantage of hysterectomy may include the loss of uterus in a woman who wishes to continue childbearing. Subtotal hysterectomy is the operation of choice in most instances of obstetric haemorrhage requiring hysterectomy. Subtotal hysterectomy is a simpler speedier operation to perform than total hysterectomy. The risk of neoplasia developing in the cervical stump several years later is not relevant in the context of life-threatening haemorrhage [26].

Use of non-pneumatic anti-shock garment, a simple neoprene and Velcro device increases peripheral resistance and consequently a rise in blood pressure, a slowing of active bleeding with improved perfusion of vital organs has also been described and has become beneficial in low-resource settings before definitive intervention [33].

Intervention radiologists, for the effective treatment of intractable postpartum haemorrhage, have used angiographic arterial embolization with gelatin sponge shavings, pledgets, coils, sponges, polyvinyl alcohol particles or balloon catheter to occlude target vessels and stop bleeding [34]. It was not used here. These approaches were not employed in this study due to lack of equipment and personnel with the required expertise. Management needs to be tailored to the particular situation and setting at hand, the experience of the obstetrician, and the facilities and personnel available.

Importantly, treatment must be prompt with monitoring and replacement of blood and clotting factors. Blood transfusion contributed substantially to the treatment modality in this study, as it was administered to more than half (56.4\%) of the patients.

Postpartum haemorrhage may lead to disastrous consequences in the parturient mother if effective control measures are not instituted. A preventable but devastating complication is severe postpartum hypotension leading to partial or total necrosis of the anterior pituitary gland with the features of panhypopituitarism or Sheehan's syndrome. This is characterized by failure to lactate, amenorrhea, decreased breast size, loss of pubic and axillary hair, hypothyroidism and adrenal insufficiency [12]. 
In this review, it is obvious that prevention is the key to reducing the incidence of PPH and its sequale, with preventive measures based upon the identification of risk factors, surveillance of women at risk and seemingly not at risk and avoidance of procedure during delivery which could potentially result in complications [20].

\section{Recommendations}

This survey has made efforts at elucidating the various clinical variables relevant in significantly affecting maternal health status and outcome in case of postpartum haemorrhage. Inadequacies identified in the provision of care to delivering women can be readily overcome through the concerted efforts of health care personnel to provide better service. The followings are recommended to ensure this.

Accessible antenatal care for all pregnant women should be ensured and junior staff and residents should be adequately supervised to improve management of high-risk case. Considering that most of the booked cases with early postpartum haemorrhage had uterine atony in this study, active management of third stage of labour which shortens the third stage by using oxytocics, cord clamping and controlled cord traction should be ensured.

Every obstetric unit should have protocols for the management of obstetric haemorrhage [35]. Access to blood transfusion facilities is essential and should be ensured. Parturients should be closely supervised in the fourth stage of labour. Traditional birth attendants and health workers in peripheral units who handle significant number of deliveries in the community should be trained and supervised.

\section{Conclusions}

In the developing world, where a very large percentage of maternal deaths occurs, it is imperative that the accoucher is properly trained on how to handle this life-threatening complication through the use of oxytocics, manual removal of placenta and provision of other aspects of emergency obstetric care, where indicated [36]. Effective management of obstetric haemorrhage depends upon prompt restoration of circulating volume, accurate diagnosis of the cause of bleeding and an early, appropriate therapy to arrest the bleeding. Underestimation of the amount of blood loss, delay in instituting definitive therapy and the performance of difficult operations by inexperienced staff appear to be frequent contributory factors to poor outcome. The resources of even wellequipped and staffed units may be stretched by massive obstetric haemorrhage; and staff (including related departments) should, therefore, be familiar with an agreed protocol that can be implemented quickly and smoothly [37].

Efficient blood transfusion services should also be made available in view of the high requirement for blood products [13]. In the special circumstance of a woman refusing blood transfusion, however, it is important not to mistake this as a desire for no intervention or an excuse for suboptimal care, regardless of the clinician's personal views [38]. Such situations should provide challenges for increased vigilance ante-, intra- and post-partum, ensuring optimal pre-delivery haemodynamic status with haematinics and possibly recombinant human erythropoietin, blood salvage, autotransfusion, collaboration with other senior and experienced staff and readiness to refer early to other centers with capability and experience in non-blood management of haemorrhage [38].

\section{Limitations of the Study}

The limitations of this study include the small sample size and the fact that hospital-based records are poorly representative of the community population. Visual estimation of blood loss generally underestimates blood loss; a biochemical assessment would be more appropriate. A multicenter study would reveal a more reflective pattern of postpartum haemorrhage in the environment than a single center study. Non-availability of full range of facilities, both medical and surgical, to tackle obstetric haemorrhage is also a limitation of this study.

\section{Conflict of Interest}

The authors declare that there is no conflict of interest with regards to publication of this article.

\section{References}

[1] World Health Organization (2012) WHO Recommendations for the Prevention and Treatment of Postpartum Haemorrhage. WHO, Geneva.

[2] American College of Obstetricians and Gynaecologists (1998) ACOG Educational Bulletin. Postpartum Haemorrhage. 
International Journal of Gynecology \& Obstetrics, 61, 79-86. http://dx.doi.org/10.1016/S0020-7292(98)90114-X

[3] Comb’s, C.A., Murphy, E.L. and Laros, R.K. (1971) Factors Associated with Postpartum Haemorrhage with Vaginal Birth. Obstetrics \& Gynecology, 77, 69-76.

[4] Chukwudebelu, W.O. (1988) Postpartum Haemorrhage and Coagulation Defects. In: Agboola, A., Ed., Textbook of Obstetrics and Gynaecology for Medical Students, Vol. 2, University Services Educational Pub. Ltd., Lagos, 212-217.

[5] Prasertcharvensuk, W., Swadpanich, U. and Lumbiganin, P. (2000) Accuracy of the Blood Loss Estimation in the Third Stage of Labour. International Journal of Gynecology \& Obstetrics, 71, 69-70. http://dx.doi.org/10.1016/S0020-7292(00)00294-0

[6] Tsu, V.D. (1993) Postpartum Haemorrhage in Zimbabwe: A Risk Factor Analysis. British Journal of Obstetrics and Gynaecology, 100, 327-333. http://dx.doi.org/10.1111/j.1471-0528.1993.tb12974.x

[7] Drife, J. (1997) Management of Primary Postpartum Haemorrhage. British Journal of Obstetrics and Gynaecology, 104, 275-277. http://dx.doi.org/10.1111/j.1471-0528.1997.tb11453.x

[8] Etuk, S.J. and Asuquo, E.E. (1997) Maternal Mortality Following Postpartum Haemorrhage in Calabar: A 6-Year Review. West African Journal of Medicine, 16, 165-169.

[9] Ratnam, S.S. and Singh, K. (1991) Towards Safe Motherhood. In: Teoh, E.-S. and Ratnam, S., Ed., The Future of Obstetrics and Gynaecology. A Preview for the 21st Century, The Partheon Pub. Group Ltd., Singapore City, 1-11.

[10] Carroll, G., et al. (2008) Epidemiology of Postpartum Haemorrhage: A Systematic Review. Best Practice \& Research Clinical Obstetrics \& Gynaecology, 22, 999-1012.

[11] Ogunbode, O. (1991) Anaemia in Pregnancy. Tropical Journal of Obstetrics and Gynaecology, 12, 19-25.

[12] Poggi, S.B. (2013) Postpartum Haemorrhage and Abnormal Puerperium. In: Current Obstetrics \& Gynaecologic Diagnosis and Treatment, International Edition. Lange Med. Pub., Los Altos, 349-368.

[13] Adetoro, O.O. (1992) Primary Postpartum Haemorrhage at a University Hospital in Nigeria. West African Journal of Medicine, 11, 172-178.

[14] Weisbrod, A.B., Sheppard, F.R., Chernofsky, M.R., et al. (2009) Emergent Management of Postpartum Haemorrhage for the General and Acute Care Surgeon. World Journal of Emergency Surgery, 4, 43. http://dx.doi.org/10.1186/1749-7922-4-43

[15] Majd, H., Nawaz, T., Ismail, L., Luker, R. and Kalla, S. (2008) Acute Uterine Inversion as a Cause of Major Postpartum Haemorrhage: A Case Report and Review of the Literature. The Internet Journal of Gynecology and Obstetrics, 12, 52-54.

[16] Wang, Y., Tanbo, T., Abyholm, T. and Henrksen, T. (2011) The Impact of Advanced Maternal Age and Parity on Obstetrics and Perinatal Outcomes in Singleton Gestation. Archives of Gynecology and Obstetrics, 284, 31-37. http://dx.doi.org/10.1007/s00404-010-1587-x

[17] Biguzzi, E., Franchi, F., Ambrogi, F., Ibrahim, B., Bucciarelli, P., Acaia, B., et al. (2012) Risk Factors for Postpartum Haemorrhage in a Cohort of 6011 Italian Women. Thrombosis Research, 129, 1-7. http://dx.doi.org/10.1016/j.thromres.2011.09.010

[18] Malkiel, A., Mor, P., Aloni, H., Gdansky, E. and Grisaru-Granovsky, S. (2008) Primiparity: A Traditional Intrapartum Obstetric Risk Reconfirmed. Israel Medical Association Journal, 10, 508-511.

[19] Selo-Ojeme, D.O. and Okonofua, F.E. (1997) Risk Factors for Primary Postpartum Haemorrhage: A Case-Control Study. Archives of Gynecology and Obstetrics, 259, 179-187. http://dx.doi.org/10.1007/BF02505330

[20] Anderson, M.D. and Etches, D. (2007) Prevention and Management of Postpartum Haemorrhage. American Family Physician, 75, 875-882.

[21] Bruce, S.L., Richard, H.P. and Van-Dorsten, J.P. (1982) Control of Postpartum Uterine Atony by Intramyometrial Prostaglandin. Obstetrics and Gynecology, 59, 47-52.

[22] Lurie, S. and Appelman, Z. (1996) Intractable Postpartum Bleeding Due to Placenta Accrete: Local Vasopressin May Save the Uterus. BJOG: An International Journal of Obstetrics \& Gynaecology, 103, 1164. http://dx.doi.org/10.1111/j.1471-0528.1996.tb09603.x

[23] Hofmedyr, G.J., Gülmezoglu, A.M., Novikova, N., Linder, V., Ferreira, S. and Piaggio, G. (2009) Misoprostol to Prevent and Treat Postpartum Haemorrhage: A Systematic Review and Meta-Analysis of Maternal Deaths and Dose-Related Effects. Bulletin of the World Health Organization, 87, 666-667. http://dx.doi.org/10.2471/BLT.08.055715

[24] Vimala, N., Mittal, S. and Kumar, S. (2006) Sublingual Misoprostol versus Oxytocin Infusion to Reduce Blood Loss at Caesarean Section. International Journal of Gynecology \& Obstetrics, 92, 106-110. http://dx.doi.org/10.1016/j.ijgo.2005.10.008

[25] El Sharkwy, I.A.E. (2013) Carbetocin versus Sublingual Misoprostol Plus Oxytocin Infusion for Prevention of Post- 
partum Haemorrhage at Caesarean Section in Patients with Risk Factors: A Randomized Open Trial Study. Archives of Gynecology and Obstetrics, 288, 1231-1236. http://dx.doi.org/10.1007/s00404-013-2896-7

[26] Orji, E.O., Ogunlola, I.O. and Onwudiegwu, U. (2002) Brought in Maternal Deaths in South-West Nigeria. Journal of Obstetrics \& Gynaecology, 22, 385-388. http://dx.doi.org/10.1080/01443610220141326

[27] Arowojolu, A.O. (2003) Managing Major Early Postpartum Haemorrhage in Developing Countries. Int. Trop. J. Obstet. Gynaecol, 20, 144-152.

[28] O’ Leary, J.A. (1995) Uterine Artery Ligation in the Control of Post-Caesarean Haemorrhage. Journal of Reproductive Medicine, 40, 189-193.

[29] Abd Rabbo, S.A. (1994) Stepwise Uterine Devascularization. A Novel Approach Technique for Management on Uncontrollable Postpartum Haemorrhage with Preservation of the Uterus. American Journal of Obstetrics \& Gynecology, 171, 694-700. http://dx.doi.org/10.1016/0002-9378(94)90084-1

[30] B-Lynch, C., Coker, A., Lawal, A.H., Abu, J. and Cowen, M.J. (1997) The B-Lynch Surgical Technique for the Control of Massive Postpartum Haemorrhage: An Alternative to Hysterectomy? Five Cases Reported. BJOG: An International Journal of Obstetrics \& Gynaecology, 104, 372-375. http://dx.doi.org/10.1111/j.1471-0528.1997.tb11471.x

[31] Smith, J. and Mousa, H.A. (2007) Peripartum Hysterectomy for Primary Postpartum Haemorrhage: Incidence and Maternal Morbidity. Journal of Obstetrics \& Gynaecology, 27, 44-47. http://dx.doi.org/10.1080/01443610601016925

[32] American College of Obstetrician and Gynaecolgists (2009) ACOG Committee Opinion No. 444: Choosing the Route of Hysterectomy for Benign Disease. Obstetrics and Gynecology, 114, 1156-1158.

[33] Miller, S., Ojengbede, A., Turan, J., Ojengbede, O., Butrick, E. and Hensleigh, P. (2007) Anti-Shock Garments for Obstetric Haemorrhage. Current Women's Health Reviews, 3, 3-11. http://dx.doi.org/10.2174/157340407779941912

[34] Wang, M.Q., Liu, F.Y., Duan, F., Wang, Z.J., Song, P. and Song, L. (2009) Ovarian Artery Embolization for Control of Severe Postpartum Haemorrhage: Report of Eight Cases. Journal of Vascular and Interventional Radiology, 20, 971976. http://dx.doi.org/10.1016/j.jvir.2009.04.049

[35] Fakoya, T.A., Oloyede, O.A.O. and Alayo, A.M. (2007) Review of Primary Postpartum Haemorrhage in Sagamu, Nigeria. Nigerian Medical Practitioner, 52, 51-54.

[36] Patton, G.C., Coffey, C., Sawyer, S.M., Viner, R.M., Haller, D.M., Bose, K., et al. (2009) Global Patterns of Mortality in Young People: A Systematic Analysis of Population Health Data. The Lancet, 374, 881-892. http://dx.doi.org/10.1016/S0140-6736(09)60741-8

[37] Mousa, H.A. and Alfirevic, Z. (2003) Treatment for Primary Postpartum Haemorrhage. Cochrane Database of Systematic Reviews, 1, Article ID: CD003249.

[38] Massiah, N., Althimulam, S., Loo, C. and Yoong, W. (2007) Obstetric Care of Jehovah’s Witness: A 14-Year Observational Study. Archives of Gynecology and Obstetrics, 276, 339-343. http://dx.doi.org/10.1007/s00404-007-0346-0 
Scientific Research Publishing (SCIRP) is one of the largest Open Access journal publishers. It is currently publishing more than 200 open access, online, peer-reviewed journals covering a wide range of academic disciplines. SCIRP serves the worldwide academic communities and contributes to the progress and application of science with its publication.

Other selected journals from SCIRP are listed as below. Submit your manuscript to us via either submit@scirp.org or Online Submission Portal.
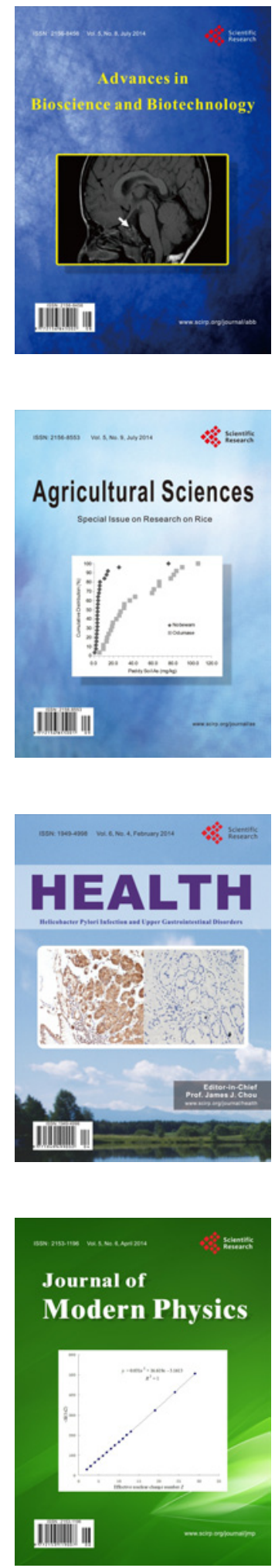
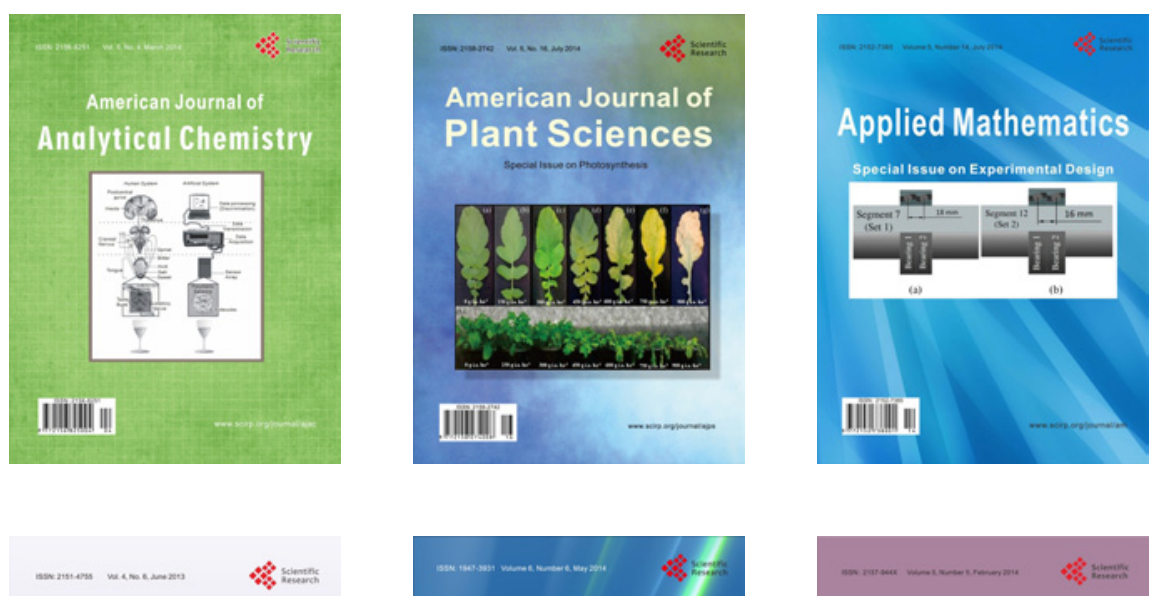

Creative Education
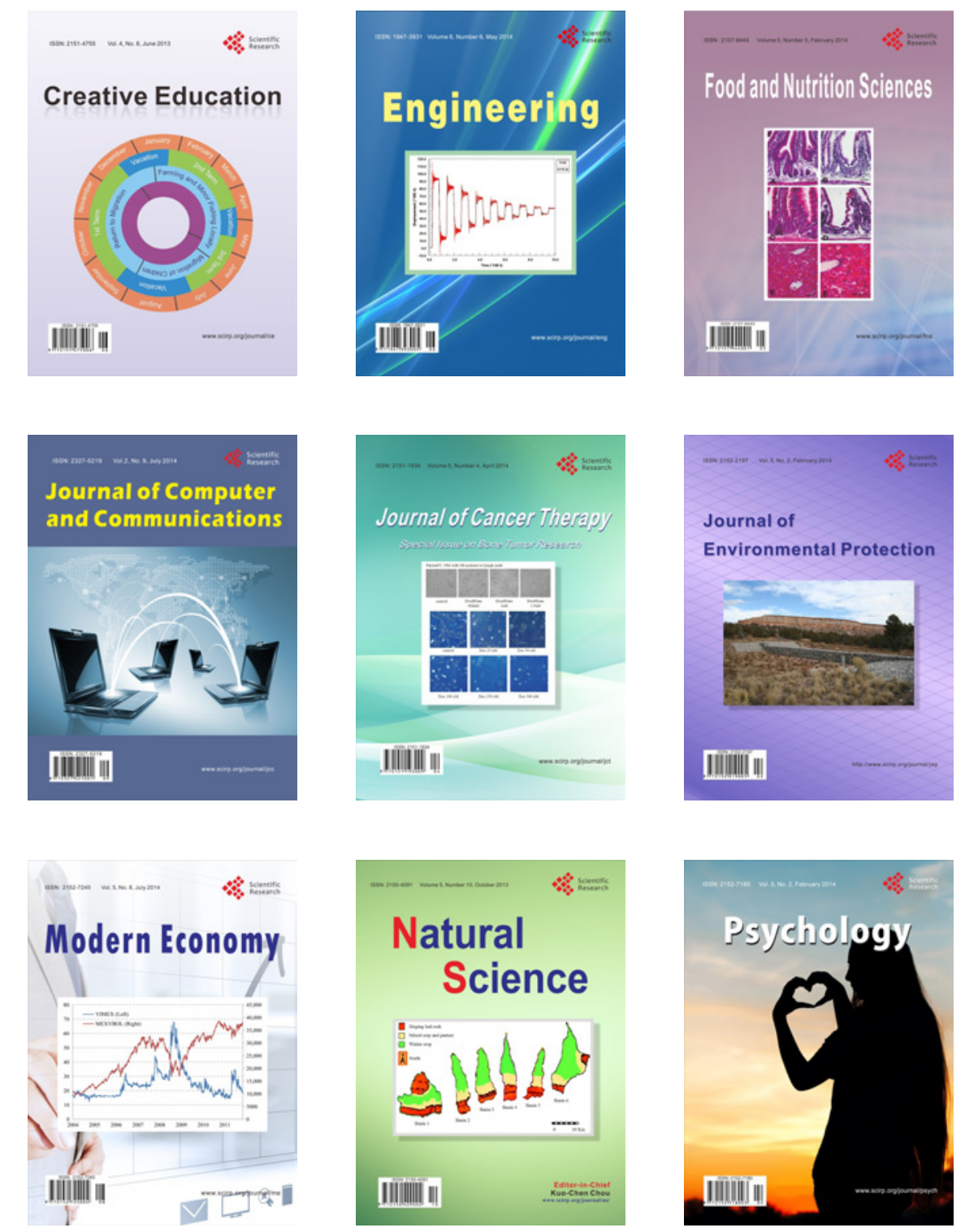